\title{
Sustainable Value Generation Through Post-retail Initiatives: An Exploratory Study of Slow and Fast Fashion Businesses
}

\author{
Rudrajeet Pal \\ Department of Business Administration and Textile Management, \\ University of Borås, Borås, Sweden \\ e-mail: rudrajeet.pal@hb.se
}

(c) Springer Science+Business Media Singapore 2016 S.S. Muthu and M.A. Gardetti (eds.), Green Fashion, Environmental Footprints and Eco-design of Products and Processes, DOI 10.1007/978-981-10-0111-6_6

Citation: Pal, R. 2016. "Sustainable Value Generation Through Post-retail Initiatives: An Exploratory Study of Slow and Fast Fashion Businesses." In Green Fashion, edited by S. S. Muthu and M. A. Gardetti, 127-158. Singapore: Springer.

\begin{abstract}
The dialogue between slow and fast fashion has gained great prominence in recent years particularly in terms of sustainability. In the forward value chain, fast fashion companies are most often considered to be unsustainable whereas the slow fashion brands are comparatively more planet-friendly. However, the discussion on the trade-off between sustainability and "speed of fashion" (classified into slow and fast fashions) in the post-retail segment is still limited. A deeper understanding, however, would not only contribute towards conceptualizing the post-retail initiatives, but would also shed light on how these are differentially undertaken by various types of fashion businesses in terms of generating sustainable value. This study proposes sustainable value generation in terms of closing the material and responsibility loops. It further reveals that the trade-off in post-retail is not as rigid as it is in the forward value chain. However, fast fashion offers the lowest potential to displace the purchase of new clothes to close the material loop whereas the redesign brands offer the highest; moreover fast fashion is less liable to take extended responsibilities compared to the slow fashion brands. It can be concluded that fast fashion is somewhat "stuck in the middle" in comparison to the slow and redesign brands in terms of generating value through closing the loop activities.
\end{abstract}

Keywords Fast fashion · Slow fashion · Post-retail · Responsibility · Business model $\cdot$ Value

\section{Introduction}

The dialogue between slow and fast fashion has gained great prominence in recent years, particularly in terms of sustainability (Clark 2008; Fletcher 2010). In the forward value chain, fast fashion companies are often considered to be 
unsustainable due to their increasing favor towards mass production and consumption. Owing to various factors, such as production in bulk quantities, cost-intensity and low quality, short product lifetime, and so on, fast fashion retailers are criticized for contributing towards a cheap, throw-away society plagued by surpluses (Birtwistle and Moore 2007). On the other hand, the slow fashion brands are considered comparatively more planet-friendly owing to their diverse practices of supporting local manufacturing, durable or timeless product designs, reuse activities, slow consumption, and the like (Fletcher 2010; Fletcher and Grose 2012).

In this growing sustainability paradigm, however, the focus towards value chains has shifted from being linear to circular. Various efforts are made by organizations in order to bring back the disposed-of products and close the forward chain material loop by using reverse logistics activities such as reuse, refurbish, repair, remanufacture, recycle, or redesign (Jayaraman and Luo 2007). This circularity of value chains has gained momentum in the fashion and apparel industry as well, as fashion businesses have started engaging with various post-retail initiatives, including reuse, recycle, remanufacture, and so on. For example, many fashion brands, including Patagonia and Nudie Jeans have started schemes to take back their old products from wearers and sell them as second-hand, either "as is" or after some redesign. These sales are conducted either through their own stores or via online marketplaces (such as e-Bay; Ekvall et al. 2014). Large retailers including H\&M and PUMA have similarly entered into collaborations, but with global sorting partners to develop efficient take-back schemes. Some of the retailers such as Marks and Spencer and Levi's have initiated similar initiatives in collaboration with charities. On the other hand, many smaller brands have started redesigning the used clothes for a longer life thus fitting into the slow fashion movement philosophy (Gardetti and Torres 2013). For example, Studio Re:design is a regional initiative in West Sweden aimed at upcycling textile and clothing wastes and leftovers from the Red Cross using slow craft principles (Studio Re:design 2014). Under this initiative many small design brands have taken part in the redesign collective to aim for attaining a circular economy by redesigning wastes. In connection many small redesign brands have eventually evolved combining traditional tailoring, repairing, and customization services to create new garments from used ones that have been donated by customers, producers, or charities. These aim at rendering sustainable solutions for handling the garments' end of life (Ekvall et al. 2014). In this post-retail market context, companies address sustainable value generation in various ways, along 5-R: reuse, reduce, recycle, redesign, and reimagine (Ho and Choi 2012) that is crucial to attain:

1. Higher resource efficiency through higher end-of-use (EOU) recovery

2. Lower virgin material consumption

3. Higher responsibility

Resource efficiency attained by closing the material loop has been designated as one of the top priorities by civil society, business, and government in order to reduce resource depletion and related environmental and societal threats (EC 2011; McKinsey 2011; Stahel 1982). On the other hand, taking responsibilities 
in closing the loop through extended product liability and stewardship of the involved actors has been prioritized by Stahel (1994).

However, the existing scholarly literature on post-retail and closed-loop value chains are limited in certain way. These have yet to explore how the post-retail initiatives and their underlying business components and drivers operate in various fashion businesses characterized by their inherent business philosophies of slow and fast fashion to generate sustainable value. Instead the existing discussion is very generic, for example, on how various fashion companies engage with diverse post-retail initiatives, and so on. However, by investigating whether the trade-off between sustainability and "speed of fashion" (classified into slow and fast fashions) as evident in forward-value chains is equally observable in postretail initiatives or not would contribute in a number of ways. First, it generates a deeper conceptual underpinning to post-retail initiatives in terms of sustainable value drivers in closed-loop value chains, that is, resource efficiency and liability. Second, by studying and comparing post-retail initiatives of various slow and fast fashion businesses similarities and differences are identified in terms of their underlying business models. Finally, the study opens up an emergent phenomenon underlying sustainable value generation in post-retail initiatives of slow and fast fashion businesses, different from that observed in case of forward-value chains.

\section{Fast and Slow Fashion Business Models}

The present day fashion apparel industry has increasingly transformed into what is characterized by short product life cycles, high volatility, low predictability, and high impulse purchase decisions by consumers (Christopher et al. 2004; Masson et al. 2007). In such an operating environment, fashion brands and retailers have increasingly started either to embrace the trend and be fast, with short development cycles, and offer large-scale production at a reasonable price, or to counter this trend and promote timeless design, slower rate of production and consumption, and so on (Clark 2008). These contrasting characteristics have resulted in development of two distinct fashion business strategies, models, and philosophies as various scholarly discussions have put it: fast fashion and slow fashion.

Fast fashion is an operational model in retailing predominantly characterized by high seasonal fashion content, affordable prices, frequent deliveries, and large quantities (Caro and Martinez-de-Albeniz 2014; Pacheco-Martins et al. 2014). This results in retailers adopting various strategies such as quick response (Serel 2014), mix of sourcing strategies from nearby and low-wage countries, supplying small quantities of new items at least twice a week (Bruce and Daly 2006), collecting daily sales data and reporting to design departments (Sull and Turconi 2008), constantly adapting design aiming to match the latest fashion trends and customer wishes, and applying flexible procurement policies (Wang et al. 2014). In connection, Bhardwaj and Fairhurst (2010) have characterized fast fashion by the expression of "throwaway," meaning overconsumption and excessive production 
of short-lived or disposable items. In order to be profitable in such a volatile business environment, fashion apparel retailers need to take the "speed-to-market" approach to capitalize on fashion that is not in the stores of their competitors thus emphasizing responsiveness and agility (Bhardwaj and Fairhurst 2010; Mattila et al. 2002). This has invariably resulted in increasing the pressure throughout the value chain in the recent years, thus increasing criticism from customers, media, and scholars due to the downsides in terms of societal impact (Plank et al. 2012; Pookulangara and Shephard 2014) and environmental problems such as higher carbon dioxide emissions due to frequent shipments and air freight (Choi 2013) among others. Increasingly, these concerns have criticized fast fashion as unsustainable as it encourages disposability, low durability, low quality, and loss of craftsmanship (Cline 2012). Some hard indicators suggest that the clothing consumption level in the western world has increased to almost $15 \mathrm{~kg}$ per capita; at this current level of consumption of natural resources we need the regenerative capacity of 1.5 Earths, and by 2050 we will need 2.3 Earths (Deloitte 2013). At the production frontier, the continuous turnover of "cheap" products equates to lower costs overall and higher volume resulting in nearly one-third of the products not sold at full price (Mattila et al. 2002).

In contrast, the ideology of slow fashion challenges the obsession with mass production, instead epitomizing diverse practices such as small-scale production, traditional craft techniques, promotion of local materials and markets, increased use of sustainable, ethically made or recycled fabrics, and development of quality garments with higher longevity (Fletcher 2010; Joy et al. 2012; Wikipedia 2015). In this context, Clark (2008) has provided several examples of local fashion and business practices associated with various aspects of slow fashion.

In many ways this offers a changed set of power relations between the fashion creators and consumers, ensuring long-term relationships and trust through higher degrees of co-innovation and transparency. Fletcher (2010) highlights that a heightened state of consumer awareness of the design process and its impacts on resource flows, workers, communities, and ecosystems can help to bring a systemwide change radically from high-volume, standardized fashion to fewer higher priced exclusive items. In connection with this, various business models have emerged promoting personalization and customization of products-doing it yourself-making, mending, customizing, altering, and upcycling one's own clothing, and so on. This way slow fashion can be seen to promote democratization of fashion not by offering more people access to clothes by lowering prices but by offering people more control over institutions and technologies.

In this context, "fast" and "slow" have become an inherent choice as a proxy for the type of fashion (Fletcher 2010). Whereas "fast" influences ideas of unsustainability, acting as a tool to epitomize increased product throughput and sales thus generating higher unethical and/or environmentally damaging practices, "slow" fashion embraces the ideas and business practices that are logically opposite to "fast," yet administers a systemwide change from the fast-growth model, exemplified by timeless design, high quality and durability, long-term relationships, and better pricing to reflect the "true" cost of the product, thus representing a vision of sustainability in the fashion sector. 


\section{Sustainable Business Models in Post-retail}

Various post-retail activities undertaken by fashion brands, retailers, and small design-oriented brands have emerged in recent times to strive for sustainable value generation (Ekvall et al. 2014). These "re" activities span over five broad areas of reuse, reduce, recycle, redesign, and reimagine, termed 5-R (Ho and Choi 2012). These "re" activities, in various ways, aim at driving higher resource efficiency, lower consumption of virgin materials, and higher end-of-use (EOU) recovery (Niinimäki and Hassi 2011), thus resulting in development of many new business models as one of the key choices for fulfilling a company's sustainable competitive advantage.

A common argument in the literature states that the business model refers to the logic of the company, including how it operates and how it creates value for stakeholders (Magretta 2002; Osterwalder et al. 2005). To date many definitions of business models have become commonly used, but these usually include three key components forming a traditional component-based view. These three business model components are (Yunus et al. 2010):

1. Value proposition: Constituted by the product/service proposed to customers

2. Value constellation: Constituted by the way the company is organized so as to deliver this product and service to its customers

3. Revenue model: Constituting the profit equation meaning how value is captured from the revenues generated

However, this definition of business models predominantly covers the facet of economic value maximization as an outcome of successful business model implementation (in for-profit businesses).

In the post-retail segment the operating business model's value generation spans beyond just generating economic profits, and covers both environmental and social profits. The environmental profit can be considered in line with what is offered in green business models. Bisgaard et al. (2012) highlight the key to develop environmental profits in terms of "substituting to greener inputs, reusing or recycling resources, offering products as a service function while continuing to have ownership of the products, or by developing greener products, services and processes." Tied to this social profits include creation of societal impact of the business in terms of job creation (Stahel 2007), generating social responsibility towards employees, and so on. Consideration of both environmental and social profits in the profit formula results in positioning the business as a change agent in the world but still with sufficient business-like characteristics (Yunus et al. 2010).

\section{Strategies for Sustainable Value Generation in Post-retail}

Post-retail initiatives in fashion apparel are still new, with limited best practices; the majority of retailers predominantly adopt two main business strategies, either second-hand retailing and/or take-back schemes (Hvass 2014). The literature has 
linked these strategies to a few generic reverse logistics tasks (Fleischmann and Kuik 2003; Fleischmann et al. 2004):

a. Strategic acquisition (or collection) from consumers

b. Grading (or sorting or disposition) into different fractions on the basis of different qualities and allocation of various reuse options

c. Reprocessing including all transformation processes for future usage

d. Redistribution for delivering the clothes again to the market

Fashion businesses can either run all these reverse logistics operations singlehandedly, by arranging both take-back of used clothes followed by reselling them through various retail formats, or can be involved in collaborative networks with a number of other partners to carry out these operations. These result in creating a number of different re-business models for generating sustainable value in used clothing value chains.

Premium and High-Street fashion brands predominantly undertake the strategy of reselling the clothes, either "as is" or after certain redesign, but only with their own branded products. Swedish fashion brands, including Boomerang and Fillipa $\mathrm{K}$ resell the used clothes that are deposited by the wearer, either in the same retail stores or in separate stores dedicated to second-hand resale (sometimes in collaboration with other dedicated second-hand retailers). These brands are in this sense closed in their collection of clothes, meaning they only take back their own brand from wearers. Nudie Jeans, another Swedish High-Street fashion brand, further engages with free repair services provided to its wearers in some of its stores (in Stockholm, Berlin, Gothenburg, and London). It also provides a repair toolkit to its wearers that can be ordered online for free. Furthermore, these brands also engage with other operations required to appropriate value of the used clothes, such as washing and redesign. Boomerang, for example, has established a concept called "Boomerang Effect" that includes a return system, a vintage collection (with used clothes meeting certain quality benchmarks and resold "as is"), and redesigning those not qualifying as vintage. These items are totally reconstructed, that is, cut and mixed with production spills to make home interior products as a part of Boomerang's Home section (Niinimäki et al. 2015). Nudie Jeans similarly engages with redesigning its denims: those are beyond repair to make denim rags, by hand-weaving them on manual shuttle looms to attain minimum energy usage.

Alternatively, many fashion retailers-mostly the large, market-driven fast fashion companies - engage with in-store take-back schemes in many ways (Hvass 2014). These take-back schemes could be organized by retailers by entering into donation partnership with charities; for example, Lindex, a Swedish fast fashion retailer, entered into collaboration with Myrorna, a Swedish second-hand retailer run by the Salvation Army (Ekström and Salomonsson 2014). Marks \& Spencer together with the charity organization Oxfam have introduced the concept of "shwopping" where wearers who hand in clothes for reuse (in either Marks \& Spencer or in an Oxfam store) receive bonus points that can be exchanged for new purchases in Marks \& Spencer (Ekvall et al. 2014). The retailers also often give away unsold leftovers or defective clothes to charities. These take-back schemes 
could also be in collaboration with third-party professional collectors as in the case of H\&M and Kappahl, two large Swedish fast fashion retailers. Both have entered into collaboration with Swiss I: Collect (I:Co), a worldwide collectorsorter, which has installed its collection containers in the retailers' store locations. These I:Co containers can usually collect up to 6-7 kg of garments which are then brought back to main storage points by existing logistics, from where I:Co picks them up and transports them to a central sorting plant. Niinimäki et al. (2015) further suggest that take-back schemes can also be organized individually by single companies, as in case of Uniqlo’s All-Product Recycling Initiative or Patagonia's Common Thread Initiative.

It can be noted that the above-mentioned business models of second-hand retailing and take-back schemes are associated with multiple R-approaches, such as reuse, recycle, reduce, and so on, and are often intertwined (Niinimäki et al. 2015). Nudie Jeans, for example, engages with repair, reuse, and recycle of its collected jeans which it calls the "Eco-cycle initiative" (Nudie 2015a). Nudie Repair shops help their wearers either by repairing worn-out jeans free of charge or by sending out a free repair kit containing threads, patches, and the like. Even possibilities of breaking down the jeans into something completely different such as a bag, or shorts is possible (Nudie 2015b). However, wearers can also give back the jeans totally, which are then washed and repaired and put back in the shop as a second-hand item. Further in the material loop, if the jeans are totally worn out then Nudie recycles them into cotton pulp or into denim strips to make upholstery (Nudie 2015c). Similarly, charities are also involved with multiple R-approaches, in general selling about $20 \%$ of the sorted items through their own second-hand stores, and the rest are exported for reuse in eastern Europe, Asia, or Africa, or are recycled (Carlsson et al. 2014; Myrorna 2015).

Apparently, these R-approaches together strive to achieve a circular economy where companies aim at closing the material loop by recovering post-consumer clothes and directing them back into the consumption cycle. Jayaraman and Luo (2007) have defined this in terms of four typical reverse logistics loops of reuse, refurbish, remanufacture, and recycle which close the forward material loop by flowing the material back at different points of the value chain. Reuse, for example, redirects the used clothes into the forward-value chain which subsequently demands marketing and sales to coordinate sales of the product "as is". In the case of refurbishing, apart from marketing and sales, outbound logistics is important to bring the product to the service providers, for washing or minor repairing, who subsequently add an appropriate value to ensure that the garment is brought back to a specified quality level and its lifetime is extended. Remanufacture or sometimes called redesign, as an R-approach instead starts with deconstruction of the garment followed by redesigning it into a completely new form. For example, Wardrobe Surgery (now called Re-dress) is a British redesign service provider that completely redesigns used garments on demand from wearers (Re-dress 2015). Many such small initiatives have sprung up with the purpose of redesigning old garments into something completely new. Finally, in Nudie and Boomerang, those products which do not meet a certain quality level are recycled; inbound logistics 
Fig. 1 Closing the material and liability loops

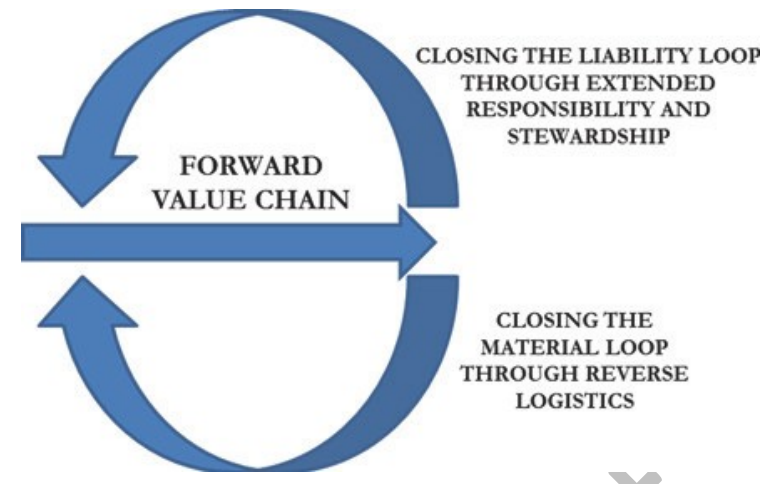

reutilizes different components of the product in conjunction with other raw materials. In this context, it is crucial to note that even though these reverse logistics loops associate different sets of operations they all contribute towards attaining a resource-efficient, circular economy.

Apart from closing the material loop by adopting various strategies to extend the product life and create resource efficiency, Stahel (1994) points out yet another necessity of closing the loop in terms of liability: through extended product responsibility. The next sections discuss these two critical drivers of closed-loop value chains in detail. Whereas driver 1 , resource-efficiency, drives for closing the material and product loops, driver 2, extended organizational responsibility (EOR), aims at closing the liability loop by extending the stewardship of the involved actors in the used clothing network, as shown in Fig. 1.

\section{Driving Factor 1: Resource-Efficient Reverse Logistics for Closing the Material Loop}

Resource efficiency in the process of closing the product and material loops highlights the attempts taken by actors for subsequent dematerialization (Stahel 1994; Tukker 2015) by:

1. Prolonging the service lifetime of products

2. Ensuring products are used as intensively as possible

3. Manufacturing products as cost and material efficiently as possible

4. Reusing products as far as possible after the end of the product's life

Stahel (1994) highlights that these activities could lead to a minimization of material flows in the economy while maximizing service output or user satisfaction, thus generating a self-replenishing system. In such a system the resource input per unit use over long periods of time can be optimized thus leading to a structural change in the economy. Apparently Stahel's work shows that the smaller the 
loop (as in the case of reuse) the higher is the profitability. The inherent drive for a resource-efficient society and businesses come from the inevitable consumption growth rate and the competition for resources in a resource-constrained world. The European Union (EU) has therefore designated resource-efficiency as one of the flagships of its Europe 2020 strategy (EC 2011). In this context, it is crucial to note that clothing is a material-intensive product and depends upon huge quantities of natural resources required for production, distribution, and maintenance, coupled with the consumer's current desire for excessive consumption (Armstrong et al. 2015). A study by Farrant et al. (2010) on the environmental benefits of reused clothes showed that consumption of natural resources such as natural gas and crude oil both can decrease by about $15 \%$ if clothes are reused through second-hand shops (in Estonia and Sweden) instead of being directly disposed of after first-hand usage. The study further concluded that the environmental burden of the product life cycle is reduced by almost $14 \%$ (in terms of global warming) through reuse of clothes.

Several commercial business strategies and resource-miser business models have been emphasized in Stahel's works (1994), (2007) including redesigning, reusing, rebuilding, technology upgrading, and the like to reduce the volume of material through the economy. Fashion businesses, however, have adopted a resource-efficiency strategy in a quite complex way. The fashion retailers and brands have adopted various strategies (as mentioned above) to attain higher resource efficiency along the R-approaches, however, at the same time provoked wearers to purchase more by providing discount vouchers on return of used clothes. Ekvall et al. (2014) have referred to this aspect in terms of displacement rate, meaning the potential of a used item to replace the purchase of a new one. The displacement rate is critical for evaluating the magnitude of environmental gains offered by various reused business models. Typically the potential for displacement, hence the degree of environmental gain, is influenced by various factors, such as quality of the resold items, percentage increase in "usage time," and discounts offered on new purchases.

Fashion brands such as Nudie Jeans and Fillipa K are engaged with reselling of their own brand and could be claimed to have a higher displacement rate due to the higher quality of resold items and higher product price compared to the average resold products. However, a WRAP study from Britain (WRAP 2013a) has indicated that the reuse displacement rate from buying a used item rather than a new one is only $28 \%$, meaning three reused items can offset the purchase and thereby the production of just one new item. Ekvall et al. (2014), however, highlight that this result is for average quality second-hand clothing and could possibly be higher for luxury second-hand compared to second-hand clothes in charity shops.

It is evident that the scholarly literature in exploring the exact impacts of displacement is quite shallow. An alternative viewpoint that exists is that this direct displacement of new purchases does not always occur in reality (Ekvall et al. 2014). Ekvall and his colleagues note in a recently published Norden report called "EPR Systems and New Business Models" that even if high-quality used clothes 
can enhance the functioning lifetime of the item (called the usage time), in the meantime a user may have saved enough money to purchase a new shirt that causes environmental impacts thus reducing the environmental gain. Ekvall et al. (2014) states that:

\begin{abstract}
Usage time is taken to mean the intensity of use multiplied by the period over which it is used. An article of clothing can last many years in someone's wardrobe without being used. In this case the lifetime might be high but the total usage time would be low. It is the usage time of an article of clothing which is key in how much it offsets the purchase of new similar clothing articles.
\end{abstract}

Furthermore, fashion retailers and brands including H\&M, Kappahl, Boomerang, and many others have started offering discount vouchers to wearers on return of clothing through the take-back schemes. These discount vouchers typically offer 10-15\% off on the next purchase of new items and do not necessarily cause displacement, and in fact may lead to higher desire for a new purchase. Simply speaking, such offers may create a perpetual voracious cycle of buying new clothes using discount vouchers obtained by depositing old ones thus adding to the throwaway culture even more. These issues have eventually made the effects of displacement rather complex to underpin, and hence can only be speculated.

\title{
6 Driving Factor 2: Extended Organizational Responsibility for Closing the Liability Loop
}

Extended producer responsibility (EPR) is defined based on two principles (OECD 2001):

1. Shifting of responsibility (physical and/or economical; full or partial) upstream toward the producer and away from municipalities

2. Provision of incentives to producers to take into account environmental considerations while product designing

EPR originated in the 1990s as an environmental policy strategy through an analysis of a number of Swedish and foreign recycling and waste management programs, as well as the use of various policy instruments to promote cleaner production (Lindhqvist 1992; Lindhqvist and Lidgren 1990). The intention behind the concept was to create a framework for governmental legislation or regulation based on the "polluter pays" principle (Ekvall et al. 2014). By definition both upstream and downstream effects are included in EPR schemes which aim for producers to gain specialized expertise (e.g., product design, materials, or technology development), utilize new resources (financial and technical), and stimulate and educate their customers to accept alternatives to landfilling and incineration and to participate in waste product recovery (Lindhqvist and Lifset 1997).

However, trade-offs exist in driving these schemes in terms of being either mandatory or voluntary, upstream or downstream, and so on in determining the scope of participation of various actors in the clothing network (Ekvall et al. 2014; Kibert 
2003). Furthermore, shifting the responsibility towards the use phase of the product is not exclusively linked to original manufacturers or producers but may also include other actors, such as charity organizations and service providers, within the product's value chain. Initiatives undertaken by brands, retailers, and other actors in the clothing network, involving product take-back, reselling, repairing, upgrading, and the like commonly extending product stewardship (Kostecki 1998), fall under the broader scope of extended organizational responsibility (EOR). Such industry-driven EOR where various actors of the value chain are proactively involved, focuses on capturing untapped value from used clothing (Hvass 2014).

According to Lindhqvist (2000) and Tojo (2004), extended responsibility of an EPR scheme can be categorized and evaluated along five different perspectives. These are:

i. Liability

ii. Economic or financial responsibility

iii. Physical responsibility

iv. Informative responsibility

v. Ownership

Liability includes the responsibility for detectable environmental damages related to a specific product. The degree of liability is, however, limited by legislation and therefore depends on the different national and regional laws and does not lie directly in the hands of the value chain actors. Presently, only a few policy-driven liability schemes exist in clothing, such as France's eco-TLC and Canadian legislation expected to commence in 2017 onwards (Kelly 2012). Next, economic or financial responsibility is used to describe an actor who will fully or partly cover the costs of collecting, recycling, or final disposal of the products and these costs could be paid either directly or through a special fee. On the other hand, physical responsibility refers to an actor taking part in the physical management of the products or the impacts of the products (Lindhqvist 2000; Lindhqvist and Lidgren 1990). Lindhqvist (2000) further defines informative responsibility as the multiple possibilities for an actor to supply information on the environmental properties and effects of its products and create awareness and understanding. Finally, if the actor retains the ownership of its products over the entire life cycle then it is automatically coupled to the environmental impacts of the products. These responsibilities are, however, not exclusive to producers alone and are equally relevant for other actors in the value chain, forming the broader applicability of EOR.

\section{Empirical Study}

The present study employs a qualitative research conducted through in-depth, semi-structured interviews and document studies to build suitable cases for the purpose of an explorative inquiry (Cresswell 2007). Extant discussion on each of the constituent concepts used in this study, viz. extended responsibilities for 
closing the liability loop, resource efficiency for driving a circular economy, along with the generic discourse on slow and fast fashions in terms of sustainability are quite established, hence a deductive approach is followed to underpin these. However, the discourse on sustainable value generation by slow and fast fashion businesses in the post-retail segment has not yet been explored thoroughly, thus advocating a theory-building perspective (Eisenhardt and Graebner 2007).

The study was conducted by collecting data from 12 fashion companies each operating in the post-retail segment in various ways. The case companies were chosen through purposeful sampling to represent the dominant fashion business models operating in the post-retail segment (Pal 2015). These are namely, fast fashion retailers, slow and fast fashion brands, and smaller redesign brands. Table 1 describes the cases in detail in terms of their post-retail initiative and underlying business model components.

Primary data were gathered through a single semi-structured interview conducted with each case company. All the respondents held top decision-making positions related to post-retail initiatives in their respective companies (e.g., sustainability manager, operations manager, or owner/managing director). Such strategic roles and responsibilities of the respondents justified their viable reflection on the topic of the present research, with low intracase differences in opinion. Each interview lasted between 45 and 60 min and was conducted in English. Each of the interviews was later transcribed and coded along themes used in both Table 1 (post-retail initiatives and underlying business model components) and in Table 2 (displacement effect and EOR).

The interview questions aimed at gaining rich descriptions of the current postretail initiatives along with detailed insights on the responsibilities undertaken by each case company. The respondents were asked to describe their company's key post-retail activities, what they offer to the customers, and how revenue was generated. In addition, questions covering EOR topics, such as ownership, type of sustainability communication, and information sharing in post-retail initiatives, collaborations with other actors, and so on were also asked.

Additionally, written documents and reports acquired through search engines were also analyzed in order to both support and validate some data obtained through the interviews. In particular, over 700 pages of reports published by the Nordic Council of Ministers, called the Norden reports, were scrutinized to supplement the data gathered. These reports are available online and free through the Norden publication database. ${ }^{1}$

For data analysis, the transcribed interviews were deconstructed to generate relevant cues; those could be categorized under the two main themes constituting sustainable value generation in post-retail initiatives, that is, extended responsibility and displacement effect. Some minor modifications have been introduced in the concepts underpinning this study to refine the deductive framework and suit it to the research context and purpose.

\footnotetext{
${ }^{1}$ Norden Publication Database: http://norden.diva-portal.org/smash/search.jsf?dswid=-1454 (02.09.2015); an extended list of these reports can be available from the author on request.
} 
Table 1 Case description with business model explanation

\begin{tabular}{|c|c|c|}
\hline Cases & Post-retail initiative & Business model components \\
\hline $\begin{array}{l}\text { Monki/H\&M } \\
\text { Swedish fast fashion brand } \\
\text { retailer }\end{array}$ & $\begin{array}{l}\text { In collaboration with a global collection, sorting and } \\
\text { recycling firm, I:Collect (in short I:Co), Monki engages } \\
\text { in taking back of used clothes under its "Second Chance" } \\
\text { program through its } 22 \text { stores. It offers strategic locations } \\
\text { in its shops for setting up I:Co’s collection containers. } \\
\text { In return gives discount vouchers to customers }\end{array}$ & $\begin{array}{l}\text { Key involved activities } \\
\text { - Strategic collection and setting of partner's collection containers in } \\
\text { shops } \\
\text { Customer value proposition } \\
\text { - Discount vouchers up to } 10 \% \text { to old wearer on return of used clothes } \\
\text { (applies to purchases over } 300 \text { SEK }^{\mathrm{a}} \text { ) } \\
\text { - Customers can receive a variety of rewards } \\
\text { - Sustainable image of extended responsibility } \\
\text { Profit/revenue generation formula } \\
\text { - Fresh purchase of new clothes by customers using discount vouchers } \\
\text { - Money from I:Collect }\end{array}$ \\
\hline $\begin{array}{l}\text { KappAhl } \\
\text { Large Swedish fast fashion } \\
\text { retailer }\end{array}$ & $\begin{array}{l}\text { In collaboration with a global collection, sorting and } \\
\text { recycling firm I:Co, KappAhl engages in taking back } \\
\text { of used clothes under its "Wear, Love, and Give Back" } \\
\text { program. It offers strategic locations in its shops for } \\
\text { setting up I:Co's collection containers. In return gives } \\
\text { discount vouchers to customers }\end{array}$ & $\begin{array}{l}\text { Key involved activities } \\
\text { - Strategic collection and setting of I:Co's collection containers in shops } \\
\text { Customer value proposition } \\
\text { - Discount vouchers of } 50 \text { SEK per donated bag to old wearer on return } \\
\text { of used clothes (applies to purchases over } 300 \text { SEK) } \\
\text { Sustainable image of extended responsibility } \\
\text { Profit/revenue generation formula } \\
\text { - Fresh purchase of new clothes by customers using discount vouchers } \\
\text { - Money from I:Collect }\end{array}$ \\
\hline $\begin{array}{l}\text { Nudie Jeans } \\
\text { Swedish fashion brand }\end{array}$ & $\begin{array}{l}\text { - Engages with repair of its own brand (wearer retains } \\
\text { the ownership) } \\
\text { - Takes back own brand from old wearers for reselling, } \\
\text { repurposing, or recycling and in return gives discount } \\
\text { vouchers, under its "Eco-cycle” program consisting of } \\
\text { Repaid, Reuse, Reduce }\end{array}$ & $\begin{array}{l}\text { Key involved activities } \\
\text { - Repair services } \\
\text { - Reselling in own stores; also includes picking and packing, } \\
\text { laundering, and repairing } \\
\text { - Clothes not qualifying for resale are either used to make denim rags } \\
\text { or sent for recycling } \\
\text { Customer value proposition } \\
\text { - Extended active lifetime of the clothes, minor redesigns } \\
\text { - Free repair service in Nudie repair shops or free sewing kit } \\
\text { - Resold branded clothes at lower price } \\
\text { - Reducing consumption of new clothes } \\
\text { Profit/revenue generation formula } \\
\text { - Purchase of second-hand clothes and denim rags }\end{array}$ \\
\hline
\end{tabular}


Table 1 (continued)

\begin{tabular}{|c|c|c|}
\hline Cases & Post-retail initiative & Business model components \\
\hline $\begin{array}{l}\text { Boomerang } \\
\text { Swedish fashion brand for } \\
\text { casual wear }\end{array}$ & $\begin{array}{l}\text { - Takes back own brand from old wearers for minor } \\
\text { redesigning or repurposing, and reselling through own } \\
\text { stores, under the concept called Boomerang effect } \\
\text { launched in 2008. Old wearer is offered discount } \\
\text { voucher on return }\end{array}$ & $\begin{array}{l}\text { Key involved activities } \\
\text { - Reselling in some of its regular stores (with new clothes) as } \\
\text { Boomerang Vintage } \\
\text { - Redesigning into interior products (Boomerang Home) for selling as } \\
\text { home textiles in own store } \\
\text { Customer value proposition } \\
\text { - Resold branded clothes at lower price } \\
\text { - Partly reducing consumption of new clothes } \\
\text { - Discount vouchers of } 10-20 \% \text { to old wearer on return of used clothes; } \\
\text { old wearer should include the personal life story of the clothing } \\
\text { Profit/revenue generation formula } \\
\text { - Sale of second-hand clothes as vintage and of interior products }\end{array}$ \\
\hline $\begin{array}{l}\text { Haglöfs } \\
\text { Swedish outdoor clothing } \\
\text { brand }\end{array}$ & $\begin{array}{l}\text { - Takes back own brand from old wearers for reselling, } \\
\text { under the concept of "Swapstories" and in return gives } \\
\text { discount vouchers to the old wearer }\end{array}$ & $\begin{array}{l}\text { Key involved activities } \\
\text { - Reselling in Haglöf's brand store (with new clothes) under the } \\
\text { second-hand concept called "Swapstories" as long as the clothes are } \\
\text { intact and clean } \\
\text { Customer value proposition } \\
\text { - Discount vouchers of } 20 \% \text { to old wearer on return of used clothes } \\
\text { - Partly reducing consumption of new clothes } \\
\text { Profit/revenue generation formula } \\
\text { - Sale of second-hand clothes }\end{array}$ \\
\hline $\begin{array}{l}\text { Beibamboo } \\
\text { Finnish baby clothes brand } \\
\text { with leasing option }\end{array}$ & $\begin{array}{l}\text { - Involved with leasing of clothes (presently } \\
\text { nonoperating in this format); retains product ownership }\end{array}$ & $\begin{array}{l}\text { Key involved activities } \\
\text { - Leasing of clothes } \\
\text { - Delivery and pick-up services } \\
\text { - Laundering (as an additional service) } \\
\text { Customer value proposition } \\
\text { - Collaborative usage of baby clothes } \\
\text { - High product quality to ensure extended lifetime } \\
\text { Profit/revenue generation formula } \\
\text { - Rental fee }\end{array}$ \\
\hline
\end{tabular}


Table 1 (continued)

\begin{tabular}{|c|c|c|}
\hline Cases & Post-retail initiative & Business model components \\
\hline $\begin{array}{l}\text { Uniforms for the Dedicated } \\
\text { Swedish slow fashion brand } \\
\text { creating timeless design using } \\
\text { recycled fibers }\end{array}$ & $\begin{array}{l}\text { - Involved with designing and producing environment- } \\
\text { friendly fashion garments based on recycled fibers } \\
\text { - Rents a small part of its collection on a short-term basis, } \\
\text { under the concept "The Collection Library" } \\
\text { - The Rag_Bag concept for donating old clothes }\end{array}$ & $\begin{array}{l}\text { Key involved activities } \\
\text { - The Rag_Bag concept } \\
\text { - Leasing of clothes } \\
\text { Customer value proposition } \\
\text { - Collaborative usage of leased clothes } \\
\text { - Sustainability image } \\
\text { Profit/revenue generation formula } \\
\text { - Prepaid ragbags } \\
\text { - Rental fee }\end{array}$ \\
\hline $\begin{array}{l}\text { Dream and Awake } \\
\text { Swedish redesign brand and } \\
\text { studio }\end{array}$ & $\begin{array}{l}\text { - Sells unique redesigned clothes } \\
\text { - Organizes redesign workshops with individual wearers } \\
\text { (wearers retain the ownership of the product) }\end{array}$ & $\begin{array}{l}\text { Key involved activities } \\
\text { - Old clothes are collected, redesigned, photographed, and sold through } \\
\text { mobile studios and online shops } \\
\text { - Redesign services through mobile studios (design, facility, equipment) } \\
\text { to wearers } \\
\text { Customer value proposition } \\
\text { - Upcycling through redesign } \\
\text { - (Re)-design co-created with wearer } \\
\text { Profitrevenue generation formula } \\
\text { - Sale of redesigned clothes } \\
\text { - Redesign charges }\end{array}$ \\
\hline $\begin{array}{l}\text { Stormie Poodle } \\
\text { Swedish designer-based chil- } \\
\text { dren wear brand }\end{array}$ & - Upcycles of high quality hotel linen into kids wear & $\begin{array}{l}\text { Key involved activities } \\
\text { - Buying of washed linen from laundry, initial sorting, product develop- } \\
\text { ment, organizing sorting and manufacturing at vocational facilities } \\
\text { Customer value proposition } \\
\text { - Value creation from industrial wastes } \\
\text { Profit/revenue generation formula } \\
\text { - Sales of repurposed products through web shops and also to retailers }\end{array}$ \\
\hline
\end{tabular}


Table 1 (continued)

\begin{tabular}{|c|c|c|}
\hline Cases & Post-retail initiative & Business model components \\
\hline $\begin{array}{l}\text { Design Stories } \\
\text { Swedish designer-based home } \\
\text { interior brand }\end{array}$ & $\begin{array}{l}\text { - Upcycles clothing wastes and production spills of } \\
\text { project partners (such as charities, second-hand retailers, } \\
\text { etc.) } \\
\text { - Organizes do-it-yourself (DIY) workshops }\end{array}$ & $\begin{array}{l}\text { Key involved activities } \\
\text { - Collection, design, and prototype development from clothing wastes } \\
\text { and production spills of project collaborators; outsourced production } \\
\text { - Co-developing repurposing processes through communication via } \\
\text { various workshops, tutorials and seminars } \\
\text { Customer value proposition } \\
\text { - Value creation from both production and consumer waste materials } \\
\text { Profit/revenue generation formula } \\
\text { - Online sales of repurposed products } \\
\text { - Workshops held at companies }\end{array}$ \\
\hline $\begin{array}{l}\text { Mocklis } \\
\text { Swedish manufacturer of folk- } \\
\text { lore and knitted socks (with } \\
\text { timeless design) }\end{array}$ & $\begin{array}{l}\text { - Engaged with upcycling of leftovers from Swedish } \\
\text { charity organization }\end{array}$ & $\begin{array}{l}\text { Key involved activities } \\
\text { - Picking of usable materials from leftovers, cutting, and repurposing } \\
\text { (outsourced sorting, laundering, and sewing processes) } \\
\text { Customer value proposition } \\
\text { - Value creation from consumer waste materials } \\
\text { - Social sustainability in engaging prisoners in workforce } \\
\text { Profit/revenue generation formula } \\
\text { - Online sales of repurposed bags }\end{array}$ \\
\hline $\begin{array}{l}\text { Skryta } \\
\text { Swedish designer-based home } \\
\text { interior brand }\end{array}$ & $\begin{array}{l}\text { - Offers design services to upcycle both post-consumer } \\
\text { clothes waste obtained from Swedish charity organization } \\
\text { and production spills }\end{array}$ & $\begin{array}{l}\text { Key involved activities } \\
\text { - Picking of usable materials from leftovers, cutting and repurposing } \\
\text { (outsourced sorting, laundering, and sewing processes) } \\
\text { Customer value proposition } \\
\text { - Value creation from both production and consumer waste materials } \\
\text { - Social sustainability in engaging prisoners in workforce } \\
\text { Profit/revenue generation formula } \\
\text { - Sales through small web shop for local designers }\end{array}$ \\
\hline
\end{tabular}

${ }^{a} S E K$ Swedish Krona 
Table 2 Qualitative rating of closing the material and liability loops by various business models

\begin{tabular}{|c|c|c|}
\hline Business model category & $\begin{array}{l}\text { Displacement } \\
\text { potential }^{\mathrm{a}}\end{array}$ & $\begin{array}{l}\text { Extended organizational } \\
\text { responsibility }\end{array}$ \\
\hline $\begin{array}{l}\text { Fast Fashion brands and retailers } \\
\text { (Evident cases: Monki, KappAhl) }\end{array}$ & Low & $\begin{array}{l}\text { Medium (1.5) } \\
\text { [IR = Partial (0.5), } \\
\text { PR + OFR = Full (1), O = No } \\
(0)]\end{array}$ \\
\hline $\begin{array}{l}\text { Slow Fashion brands } \\
\text { (Evident cases: Nudie Jeans, } \\
\text { Boomerang, Haglöfs) }\end{array}$ & Low or Medium & $\begin{array}{l}\text { Medium-to-High (2) } \\
{[\mathrm{IR}=\text { Full }(1), \mathrm{PR}+\text { OFR = Full }} \\
\text { (1), O = No (0)] }\end{array}$ \\
\hline $\begin{array}{l}\text { Slow Fashion brands with leasing } \\
\text { (Evident cases: Beibamboo, } \\
\text { Uniforms for the Dedicated) }\end{array}$ & Medium & $\begin{array}{l}\text { High (3) } \\
\text { [IR = Full (1), PR + OFR = Full } \\
\text { (1), O = Full (1)] }\end{array}$ \\
\hline $\begin{array}{l}\text { Slow Redesign brands } \\
\text { (Evident cases: Dream and Awake, } \\
\text { Stormie Poodle, Designstories, } \\
\text { Mocklis, Skyrta) }\end{array}$ & High & $\begin{array}{l}\text { Medium (1.5) } \\
{[\text { IR = Partial (0.5), }} \\
\text { PR + OFR = Full (1), O = No } \\
(0)]\end{array}$ \\
\hline
\end{tabular}

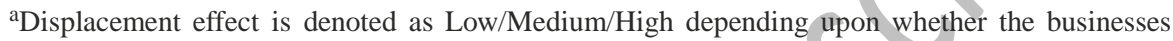
do/partially do/do not offer a scope to purchase new clothes through its business

${ }^{b}$ Extended organizational responsibility is denoted as Low/Medium/High depending upon whether the businesses takes no/partial/full liability in managing the post-retail initiative. It is cumulative regarding three constituent responsibilities: information responsibility, physical + outsourced financial responsibility, and product ownership

First, resource efficiency forms a very crucial base in this study for defining sustainable value generation in post-retail businesses, and this is measured in terms of displacement potential. The displacement potential is recorded along a threepoint Likert scale (high-medium-low) depending upon whether the post-retail initiative does or does not offer any possibility of purchasing new clothes through its business. The displacement effect is high if no such possibility is offered, for example, in case of reuse, and it is low if discount vouchers are offered to wearers on return of old clothes. However, the correlation is much more complex in reality as there are other intervening factors deciding the displacement potential.

Within the scope of EOR, considering that there is no current legislation for producers or importers to take responsibility for the environmental impact, waste management, and disposal of their products (in the countries from which the cases have been selected), liability as a responsibility was not further investigated. Additionally the financial responsibility was adapted into outsourced financial responsibility in order to differentiate those actors who solely pay third parties to take care of their products. Even though physical and informative responsibilities can be strictly executed by one actor in the value chain itself, they are always connected to labor and resource costs, and therefore finances, which are not considered in the existing literature. Thus based on this logic one could argue that every actor that takes over physical and/or informative responsibilities is also financially responsible. The extended responsibility was measured along its three components, information responsibility (IR), physical and outsourced financial 
responsibility (PR and OFR), and ownership (O) using a similar three-point Likert scale (high-medium-low). If cues from the transcribed interviews or written documentation were obtained supporting each of these components then they were scored as 1 , otherwise 0 . This denotes whether the company takes no/partial/full liability in managing the post-retail initiative.

\section{Post-retail Initiatives and Underlying Business Models}

\subsection{Key Activities in Post-retail Initiatives}

The study showed that the fast fashion businesses (Monki/H\&M and KappAhl) predominantly engage with product take-back schemes through strategic collection of used clothes in their stores. Such activities are organized in collaboration with global sorting partners such as I:Co or Kicki. Collection takes place in containers of 6-7 kilo capacity and on deposition wearer receives a discount voucher for use during a subsequent new purchase.

The slow fashion brands, on the other hand, engage with a wider range of activities, including collection, refurbishing through repairing, laundering, and so on, and reselling. These brands generally organize these multiple reverse logistics activities under a marketable concept or program; for example, Nudie Jeans under its "Eco-cycle" program offers its wearer scope to repair broken jeans either at the Nudie Repair Stores or by using DIY repair kit, free of charge. Through its website Nudie offers its wearers the possibility to fill in a form to dispatch the repair kit needed to mend the broken jeans. Such a repair kit typically contains denim patches, iron patch, needle, spool of thread, repair kit booklet, and thimble. In addition, reselling is also organized by these slow fashion brands either in the regular stores, as in the case of Boomerang and Nudie, or in different stores dedicated to selling second-hand items of their own brand, as done by Filippa $\mathrm{K}$. Furthermore, these brands also take care of washing the garments, and picking and packing them before they are put out for sale. Boomerang organizes such resale through seven stores selling its own brand, four of which are located in Stockholm. Ekvall et al. (2014) report that since the start in 2011 Boomerang has collected around 7000 garments annually. Nudie Jeans similarly gives a reuse option to its wearer, by offering possibilities either to make minor patchworks to extend the life of the jeans, or to make something completely different by reconstructing the jeans into a bag or shorts. Otherwise, wearers could donate their old jeans which are then washed and repaired and put back in the shop as second-hand items only if they achieve the Swedish "Good Environmental Choice" eco-label standard. Sometimes, Nudie Jeans is also involved in collaborations with designers and other creatives under the program "Denim Maniacs" to give worn-out jeans a second life. Haglöfs engages with a similar program aimed at reselling their own brand as second-hand. Some of the other slower fashion brands have ventured into leasing and renting business models, in addition. For example, two such brands 
observed this study-Beibamboo and Uniforms for the Dedicated-engage with leasing a specific section of its clothes. Alongside they are involved with other service provisions necessary to appropriate the leasing activity, such as laundering, delivery, and picking services. However, due to several management reasons Beibamboo discontinued its leasing concept 3 years after its start. During its operation period, the business had about 25 customers who could either opt to rent a mini- set with 6 pieces of baby clothes or a basic set with 15 pieces (Ekvall et al. 2014). Uniforms for the Dedicated, on the other hand, is involved with renting a small part of its collection consisting of selected suits and outerwear on a shortterm basis (for a maximum of a week) through its store in Stockholm.

The smaller slow fashion, on the other hand, engages more with redesign activities. Although some of them are totally based upon the redesign philosophy, as in case of Dream and Awake and Stormie Poodle, the others include some redesign alternatives in their regular slow design collections. The redesign activities are mostly conducted with used clothes or textiles, either bought or collected from other actors in the used clothing network or individual wearers. Stormie Poodle, for example, works with reconstructing hotel linen into kidswear by buying washed linen from the laundries followed by initial sorting of the material in Sweden. The linen is then sent to Latvia for a second sorting in collaboration with vocational schools. Dream and Awake, on the other hand, collects or buys old vintage clothes from the market and redesigns, photographs, and finally sells them through mobile studios. It is also involved with organizing redesign workshops with wearers in providing designs, facilities, and equipment to help them redesign their own clothes. Working with a slightly different format, the slow fashion brands organize redesign activities by working with charities including the Red Cross, to collect textile wastes and leftovers from them. These materials are then redesigned to develop prototypes in the studios of these redesign brands. Other supporting activities such as sorting, washing, and sewing are usually outsourced to other organizations including social institutions such as prisons and disability homes. Mocklis, for example, works in collaboration with Syverket, a company that sorts the wastes thus helping the brand to pick up the usable materials; this is followed by organizing sewing activities at the workshops in prisons. In addition Mocklis also utilizes small local production facilities to produce the final redesigned products (bags). Design Stories, in a similar way, works with another charity-led organization called Emmaus, to get diverse materials such as plastic bags and fabric. It collects production spills from other companies to fuse these materials to make slow craft hand-made lamps.

\subsection{Customer Value Proposition (CVP) of Post-retail Initiatives}

The fast fashion businesses aim at generating a sustainable brand image to their customers through involvement with post-retail initiatives. Both Monki/H\&M and KappAhl share extensive information about their collaborative garment collection 
schemes through company websites and social media to show their commitment towards making a change in the garment life cycle. Through their programs, "Second Chance" and "Wear, Love, and Give Back," respectively, these businesses quite explicitly share information about the post-retail objectives as an integral part of company values. Monki, for example, clearly specifies "Second Chance" in their website under company values and as an integral part of their "way of doing business." KappAhl (and also H\&M), on the other hand, considers and reports such initiatives under "Our Responsibility" in their websites. In addition, fast fashion businesses also offer discount vouchers to all wearers on donation of old clothes under different schemes, either as $10-15 \%$ off or as a monetary discount (50 SEK) on new purchases over 300 SEK.

The slower fashion brands, such as Boomerang, Nudie Jeans, and Haglöfs, also engage in a similar way to offer value to their customers, by offering discount vouchers ranging between $10-20 \%$ to the old wearer on their return of used clothes. In addition these brands also try to tell a story to its wearers through the process of reselling. Haglöfs, for example, under its second-hand concept of "Swapstories" narrates a story written by the garment's previous owner about what they have experienced together with the product (Reuters 2012). Such stories can be submitted in advance via the Swedish Haglöfs website, where it is possible to read other people's stories as well. On submitting a story along with returning a garment a higher discount can be obtained. Nudie Jeans, on the other hand, maintains one of the most comprehensive websites where it shares detailed information on every step of its “Eco-cycle”: break-in, repair, reuse, and recycle. Nudie's storytelling to its wearer is based upon a transparent inscription of all its processes and operations through blogs, videos, and guides, and flowcharts posted through its website, thus offering a unique value and sense of responsibility to its wearer. Free services in the form of in-store repairing and sending out of repair toolkits are a part of the extended value proposition and brand strategy of Nudie Jeans. As highlighted by Niinimäki et al. (2015) both Nudie Jeans and Boomerang use this strategy to endorse their brand and communicate sustainability. To some extent such transparency in communicating information explicitly portrays these brands' initiative to attain a circular economy and resource efficiency.

On the other hand, the fashion brands engaged with leasing activities focus on offering their wearers the benefits related to collaborative consumption. In case of Beibamboo, typically the benefit offered to the babies' parents was in terms of payment of a small fee to receive a set of 5-12 clothes rented over a long period of time, till the babies outgrow the size. Additional services such as delivery and pick-ups were also arranged by the brand along with washing and regular care of the clothes.

In general the redesign brands, however, focus more on the redesign aspects of the product through upcycling. These brands claim to reinvigorate and redefine the old into something new. Dream and Awake, for example, claims that in doing so it adopts a "social + green" business model format as it uses no virgin material during its production and the social aspect is maintained by paying a fair sum of money to the tailors. Along with this, the wearers are also offered the feeling 
of wearing "unique pieces," available in one sample only, very similar to having a customized vintage garment. Stormie Poodle similarly generates a combination of the "social + green" business model by utilizing old hotel linen as the starting raw material and further carrying out the production at vocational facilities in the Baltic countries to support social development. Mocklis and Skyrta, on the other hand, build upon their social aspects of sustainability by engaging prisoners from the jails and handicapped people. In all, these brands highlight their resource efficiency and circularity through upcycled design to underpin their sustainability image, thus proposing value to the wearer or user.

\subsection{Revenue Generation from Post-retail Initiatives}

Revenue generation is a critical requirement of all business models. Such revenue generation in "social + green" business models stands on three pillars: social, environmental, and economic profits. In the case of the post-retail initiatives, balancing these three profit formulas significantly keeps the "social + green" business model operating sustainably. Although this section only highlights economic profit as a component of traditional business models, the environmental and social profits are reported as sustainable value generators in closed-loop value chains, in the next section.

The fast fashion companies receive some money from the sorting partners in supporting the in-store collection activities although most of it is donated to charities and for societal causes. Monki, for example, reports that it receives money from I:Co even though any earnings made are split between H\&M's research fund and Plan International's “Because I Am a Girl” project. However, a big share of revenue is generated indirectly from the post-retail business format by offering discount vouchers. Such discount vouchers are expected to generate higher purchases of new items thus resulting in sufficient revenue generation.

The slow fashion brands mainly generate revenue in two ways. Similar to the fast fashion companies these brands also provide discount vouchers to the wearers thus creating an indirect revenue generation stream from their post-retail initiatives. Apart from that, resale from second-hand clothes sufficiently generates revenue as well. Boomerang, for example, sells its second-hand vintage collection through regular stores at a price range between 300-500 SEK, whereas the Boomerang Home products in the Effect Collection made from fabric offcuts are sold at a much higher price. Similarly, Nudie Jeans sells its rag rugs made from denim rags at a price range between 1999-5999 SEK. However as reported in Palm et al. (2014), Haglöfs did not gain any money from the sale of its secondhand items due to its high amount of charitable donations (Palm et al. 2014).

The redesign brands in a similar way price their upcycled products quite high as revealed through the study. Mocklis, for example, priced its upcycled bags between 1000 to 2200 SEK whereas Skyrta sells its lamps on-demand (made out of Red Cross's leftovers) at over 5000 SEK per piece. However, most of these 
small-scale redesign brands work on the redesign business as either an experimental or start-up project alongside their main business model of selling slow fashion design, mainly due to the long break-even periods in the upcycling business and other inherent challenges to it, such as high costs of sorting and low recovery rate among others. Stormie Poodle, for example, highlights the high cost of redesigning in Sweden and the long manufacturing time required to redesign each product manually.

\section{Post-retail Initiatives and Closing the Loop}

\subsection{Closing the Material Loop by Displacing New Purchase}

Fast fashion businesses communicate their post-retail collection initiatives in collaboration with other partners as an attempt to close the material loop to attain a resource-efficient circular economy. However, several recent investigations criticize these efforts, considering them to be merely a part of branding and marketing (Ekvall et al. 2014). The recent debate on whether fast fashion companies are actually sidestepping the issues of overproduction and consumption by showcasing these post-retail initiatives is steadily gaining prominence (Guardian 2015). In this context, the potential to displace the purchase of new garments serves as one of the possible indicators of such a closed loop process. However, this is one of the major drawbacks of the attempt to close the loop undertaken by the fast fashion companies. They engage just with collection of the used clothes and in return provide discount vouchers worth 10-15\% off from the new purchase from their own stores, resulting in a low degree of displacement potential. Customers are now simply attracted towards a perpetual environment of discounts available year-round in the stores: one of the key drivers of a throwaway economy thus depositing more and more of their old clothes and in return buying new ones. With limitations of the currently available technologies complete separation of the mixed fibers into constituents is still a tale of the future, and thus does not really support the claim that recycling the donated clothes would rechannel the entire material into the resource pool once again at the same rate at which virgin materials are utilized. Moreover, each turn of fashion also creates a huge carbon footprint, even if it's in the loop.

The slow fashion brands in spite of offering similar discount vouchers to the customers on donation of their used clothes further engage with resale of secondhand items. Such resales not only extend the lifetime of the old garments but are expected to replace the purchase of new items as well thus having considerable potential to displace new purchases. Furthermore, such reuse material loops are expected to have considerably lower carbon footprints and impact on natural resources (Farrant et al. 2010). The leasing slow fashion brands go a step farther in their effort to increase displacement of new purchases. They possess the positive potential as also rendered by resale through extension of the usage lifetime of the 
product. In addition, they promote collaborative consumption thus satisfying multiple users, as also highlighted by Mont et al. (2006). This significantly increases the usage time of each product (as a ratio to its shelf life) thus having the potential to have a higher displacement rate. However, this relationship is not simple as in the meantime the wearer/shopper may save enough money to buy a new one, thus upsetting the benefits that displacement gained.

In comparison, the redesign brands offer a much higher displacement effect as they rarely utilize virgin materials to manufacture new items. Instead these brands are constantly upcycling old used materials and rechanneling them into the consumption cycle, thus having significant impact.

Overall, in terms of resource efficiency (measured by the potential to displace the purchase of a new one), the redesign brands show the best results in terms of displacement potential: to replace the purchase of new clothes by the resale of redesigned old clothes. The slow fashion brands are also considerable in terms of their displacement potential countering the negative impacts of offering discount vouchers to stimulate new purchases. However, the fast fashion companies prove to be the worst among all considering their sole endpoint to closing the loop activity is by stimulating new purchases.

\subsection{Closing the Liability Loop Through Extended Organizational Responsibility (EOR)}

The fast fashion companies, Monki and KappAhl, show low physical responsibility in managing used clothes beyond their in-store collection in the I:Co containers. Responsibility is limited in terms of just offering space for placement of the collection containers. However, further stewardship of sorting and reselling/reusing/recycling these collected items is financially outsourced to I:Co through a strong partnership, I:Co maintains a well-established automatic collection and logistics network to transport the collected used clothes to its Wolfen Textile Recycling Plant. It is still unclear "who pays whom" in this collaboration. Interviews suggest that it is the brands and retailers who pay a fee to I:Co to install these containers thus undertaking a financial responsibility in outsourcing the physical management of the waste. On the other hand, company websites suggest otherwise; for example, Monki reports that it receives money from I:Co even though any earnings made are split between research and charitable work.

Information responsibility in the case of these fast fashion companies is communicated very clearly through company websites, marketing campaigns, and other social media. This has become an integral part of their brand strategies and an avenue to communicate their sustainability image. Most of the time, the information on post-retail initiatives and collection schemes are documented either in the company's sustainability report and can be found under "core value" in the company's website. Monki, for example, conveys information about its "Second Chance" program, along with other corporate social responsibilities under "Monki 
Values”. However, interestingly, none of these fast fashion companies provides a transparent and holistic view of the entire closing the loop process, meaning that it is unclear what happens to the collected items once they are received by I:Co. Do they end up in Africa or some other developing regions, and so on? The figures projected are also very coarse; for example, $30 \%$ is recycled as stated on I:Co website. The fast fashion companies do not refer to details of traceability of the products once collected through their stores, even though they claim to disagree on this issue. Some fast fashion companies do deposit their leftovers to I:Co which can be traced back from their brand logos, until they are debranded.

The slow fashion brands, Nudie Jeans, Boomerang, and Haglöfs, on the other hand, exercise a high degree of physical responsibility towards managing the used clothes of their own brand collected through their stores. Such liabilities as discussed earlier include collection, refurbishing services, along with reselling and recycling thus representing multiple reverse logistics processes. These brands sell the clothes as second-hand directly through their own stores only after they attain a certain quality standard. Those that do not pass the quality test are instead converted to a completely different product category. Nudie Jeans, for example, engages with collection of its own used brand through its stores, provides free repair services to wearers in case they want to extend their period of use of the jeans, and in other cases takes back the jeans from the wearer to wash, repair, and put them up for resale. Only those jeans which have achieved the Swedish "Good Environmental Choice" eco-label are resold, and the rest are recycled to make something completely different out of the denim rags. Nudie's recycled product range includes carpets and camper seats. Similarly Boomerang's concept of "Boomerang Effect" includes a holistic management of their used own brand through a return system, reselling vintage and redesigning the rest into interior home decors.

Communication of information related to such comprehensive post-retail initiatives is also done in a very systematic way. Niinimäki et al. (2015) suggest that wearers and shoppers who are actively interested in sustainability look for related information and news primarily through the company websites apart from in-store communication of sustainability. Lack of special campaigns and immediate firstpage information on the company website invariably results in not capturing the attention of the less proactive customers. In this context, Nudie Jeans is a pioneer in communicating its efforts transparently through its website. It has a very dedicated website that conveys all its post-retail initiatives and processes. Not only do all these brands use their regular stores to communicate their story to the wearers, but Nudie by setting up its repair shop inside the regular shop, and Boomerang and Haglöfs by mixing reselling of second-hand with new ones in regular stores also reach out to the consumer. In addition, Nudie Jeans also offers its wearer a multitude of information, both audiovisual and readable, including washing guides, self-repairing booklet, end-of-life possibilities, and the like to communicate the services and other actions for becoming more sustainable. Overall, these brands engage in a very high degree of information responsibility.

In an alternative business model based upon leasing, Beibamboo exercises complete physical management of the clothes to and from each wearer along 
with its maintenance through washing and minor repairs if required. Furthermore, under the leasing model the brand also retains complete ownership of the product throughout its lifetime. Similarly in autumn 2013 Uniforms for the Dedicated also selected some parts of its collection for short-term leasing in its store in Stockholm thus contributing towards communicating careful shopping (Niinimäki et al. 2015). It also communicates such efforts through its official website, and the rental concept is labeled as "The Collection Library." Here interested renters can read about the idea of what it calls "time share" and can get all practical details and terms related to renting a Uniforms for the Dedicated product. In addition, its owner Mike Lind considers the use of store as the platform to communicate these efforts to customers as not many of them are totally aware of the concept.

Redesign brands are also at the forefront of taking physical responsibility of the wastes and used clothes that are neither produced nor imported by them. However, this is executed in a slightly different way. These companies either buy or receive various kind of wastes, such as clothing wastes (in the case of Mocklis, Skryta, and Dream and Awake), production spills (in the case of Design Stories), and used textiles (in the case of Stormie Poodle) from a number of suppliers or partners including charities, retailers, or even individual people. These suppliers or partners can be commercial, such as the hotels supplying used linen in the case of Stormie Poodle or nonprofit charities in the case of Design Stories, Mocklis, and Skryta. After collection, these small redesign brands engage with design and prototype development. Considering the relatively small size of business, these redesign brands have limited financial and infrastructural leverage, hence they are compelled to outsource many of the value-appropriating services, such as sorting, washing, and sewing required to regenerate value of the upcycled product to prisons or to other service-providing companies.

Furthermore, information responsibility of these small-scale redesign brands are predominantly through physical platforms, such as training sessions and workshops as compared to communication through websites. Dream and Awake, for example, communicates its redesign potential to the wearers through its mobile redesign studio offering a suitable space, tolos, and materials as well as skills and knowledge to those who can redesign their own garments. Design Stories similarly conducts workshops for instructing and developing the redesign processes together with others (partners and clients). Such workshops are conducted at many places, including colleges, companies, and organizations and cover several different topics, for example, design process, sustainable design, design and waste, energy, and design, among others. It further shares certain cases and project stories through its website. However, both the responsibility and the amount of information communicated by these brands are not as extensive as can be found in the case of the large slow fashion brands, heavily focused towards brand development. Instead these efforts are mainly small-scale and project-oriented. The other brands incorporated in the study merely communicate any further information on their post-retail initiatives through their websites apart from just portraying themselves as slow fashion.

Overall, it can be highlighted that the slow fashion brands exercise the highest degree of responsibility through their post-retail initiatives. This is attributed 
by more holistic physical management of their own used brand by undertaking multiple reverse logistics activities, along with extensive efforts taken in communicating sustainability. In fact these slow fashion brands epitomize their postretail concepts and initiatives through social media, particularly their websites and stores, in such an explicit way that customers without the slightest hesitation can grasp their core business priority. Fast fashion brands and retailers and the small redesign brands follow next in terms of their total liability towards closing the loop. Although the fast fashion businesses do outsource most of the activities concerning physical management of the used items through partnership, they financially bear the cost of it. Furthermore, these fast fashion businesses engage in mega events and competitions to exemplify their efforts although a deeper look may raise issues related to transparency in information sharing along the revalue chain. The redesign brands undertake physical management of the items in a slightly different way. Even though these brands outsource most of the value appropriation activities such as washing, sewing, and the like, they take complete responsibility in upcycling leftovers and wastes of other actors to make something new and valuable. However, possibly due to financial limitations owing to the smaller size these brands have a lower level of communication efforts through various channels.

Table 2 summarizes the above discussion in terms of closing the material and liability loops and establishes a qualitative rating of the sustainable value-generation efforts for each business model category.

\section{Brand Positioning: Are the Fast Fashion Businesses "Stuck in the Middle"?}

With the increasing cults of throw-away fashion and hence growth of textile wastes, the post-retail segment offers business opportunities for fashion companies beyond just recyclers, charities, and second-hand retailers (Hvass 2014). The postretail segment and businesses associated with it are nothing new and for several decades copious activities such as donation of used clothes to charities, reselling used clothes in flea markets, and so on have existed, even though the system of diverting wastes to landfill and/or energy recovery still maintains the majority. However, recently in light of the unsustainable practices of the textile and fashion industry resulting in depletion of the world's resources and environmental problems gaining prominence (Birtwistle and Moore 2007), fashion businesses are increasingly undertaking post-retail initiatives to overcome their unsustainable practices and image. Hvass (2014) highlights that in such an environment, fashion companies are increasingly rethinking their existing value propositions and collaborations with a multitude of stakeholders to devise sustainable solutions for closing the loop. The relation between sustainability and fashion business models in the case of forward value chains is pretty straightforward, concluding that the resource-hungry, cheap fast fashion businesses are unsustainable, whereas the 
slow fashion brands built upon timeless design, high durability, and green concepts are more sustainable in nature (Fletcher 2013). However, the relation is less explored when it comes to different post-retail initiatives undertaken by fast and slow fashion businesses.

Post-retail responsibilities for these fashion companies, in general, can be distinguished predominantly into two main categories, second-hand retailing and product take-back schemes, and are increasingly driven by the demands of generating a circular economy (Ellen McArthur Foundation 2013). The key environmental factors driving these operating post-retail business models aim towards generating a resource-efficient circular economy, and have been prioritized by all important actors in civil society, business, and government. These drivers fall back to the notion of closing the loop both by:

1. Recirculating the raw materials back into the consumption cycle in infinite loops

2. Taking extended liability or responsibility in handling the material reflow and related information

Although the first closing the loop process is conducted through reverse logistics activities following the five-R (i.e., reuse, reduce, recycle, redesign, and reimagine) approach to take care of the tangible flow, these additionally extend the intangible liabilities or responsibilities of the companies in managing the circularity.

In this context, traditional business model components, viz. key activities, customer value proposition, and economic profit formula (Magretta 2002), cannot alone define the success and value generated through these businesses. Sustainable value generation in this context involves closing both the material and liability loops to attain a resource-efficient circular economy and exercise extended organizational responsibility.

Although implementing a closed material loop through post-retail initiatives, it can be concluded that the fast fashion companies show minimum resource efficiency owing to their business strategy of offering discount vouchers to customers on donating used clothes. In such a case, the potential to displace the purchase of a new item is considerably low owing to the possibility that customers get induced into the spiral of throwing way old stuff from their wardrobe more frequently than ever to get discounts on new purchases. In fact such a spiral can increasingly lead to a scenario of perpetual discounts available year-round in the stores, a symbol of fast fashion culture (Bhardwaj and Fairhurst 2010; Birtwistle and Moore 2007). On the other hand, the small redesign brands offering no possibility to buy products made out of virgin raw materials can be considered to offer higher displacement potential.

Findings from the current study further show that in the liability loop, product stewardship executed by the fast fashion businesses is comparatively lower than the slow fashion brands'. Out of the two predominant business strategies highlighted by Hvass (2014), the fast fashion businesses only undertake product take-back schemes through their retail stores, whereas the slow fashion brands combine it with reselling as a part of their post-retail responsibility. Furthermore, 
some of the slow fashion brands follow a leasing business model thus taking complete ownership of the products throughout its extended lifetime thus increasing the extent of responsibility undertaken. In addition, lack of traceability and of communicating transparency regarding used clothes flow further decreases credibility for the collectors (fast fashion companies), hence their commitment in postretail activities as perceived by the wearers (Palm et al. 2014). Even though there is an increasing need to communicate more information regarding the treatment of the collected clothes, not much has been done by the retailers to address this issue. With a higher degree of control on the post-retail initiatives the slow fashion brands possess and also communicate their efforts more transparently through social media and various other channels. Overall, the fast fashion businesses are positioned quite delicately in terms of generating their sustainable value in the post-retail initiative, as shown in Fig. 2.

The main challenge of the fast fashion business model in terms of the sustainability advantage in generating value in post-retail market, as depicted in Fig. 2, can be labeled the "stuck in the middle" challenge. On one hand the fast fashion businesses show a lower level of responsibility compared to that executed by the slow fashion brands, whereas in terms of displacement potential they can be rated the least.

Even though it emerged that the trade-off between sustainability and "speed of fashion" is not completely dichotomized in the case of post-retail initiatives,

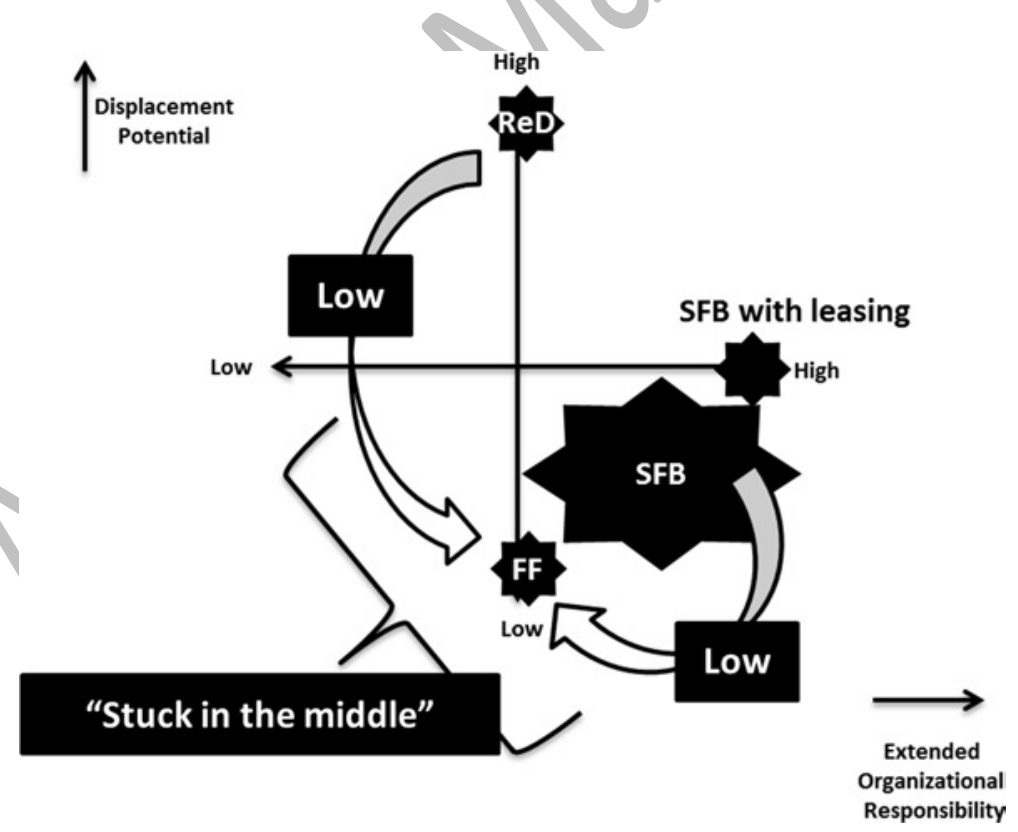

Fig. 2 Brand positioning in post-retail segment. FF Fast fashion businesses, SFB slow fashion brands, $R e D$ slow redesign brands 
and fast fashion businesses do execute considerable stewardship in "responsibility management," they are, however, under competitive pressure from both slow fashion and redesign brands in terms of closing the liability and material loops, respectively. In this context it could perhaps be concluded that the "stuck in the middle" positioning of the fast fashion companies may eventually reduce their sustainability advantage due to emerging pressures from both sides by slow fashion and redesign brands.

\section{Conclusion}

The purpose of this study was to explore whether the trade-off between sustainability and "speed of fashion" in fashion business models (classified into slow and fast fashions) as evident in forward value chains is equally observable in postretail initiatives. In this context, this explorative study sheds light on various issues related to post-retail initiatives taken in the fashion industry in terms of sustainable value generation and strategic positioning of various operating fashion business models. First, a deeper understanding of diverse post-retail initiatives undertaken by various fashion businesses is presented, and is thematically analyzed into traditional business model components, viz. key activities, customer value proposition, and profit formula. The study categorized these fashion business models into four broad types: fast fashion, slow fashion, slow fashion with leasing, and redesign, based upon the differences underlying their business model components. A deeper conceptual underpinning to post-retail initiatives is provided in terms of closing the loop, viz. material efficiency and liability. Secondly, the study advances the understanding of the source of sustainable value generation in the post-retail market in terms of closing the material and liability loops, thus adding to environmental and social profit generation. This way it conceptualizes the success drivers of post-retail businesses. By analyzing these post-retail initiatives of various slow and fast fashion businesses, the study shows that the trade-off between sustainability and speed is not as rigid in the case of the reverse value chain as it is in the forward value chain, probably because there is always an aspect of greenness and social responsibility rendered by all businesses when operating in post-retail. However, the fast fashion businesses are somewhat in a "stuck in the middle" position in comparison to the slow and redesign brands along the material and liability loops.

Future research along this line can explore various possibilities. Quantitative and simulation studies can be conducted to explore the role and benefits of both displacement potential and product responsibility in closing the loops to attain higher resource efficiency and liability. These studies can delve in detail into many issues, including consumer purchase behavior with and without discounts, effect of redesigning on new purchases, effect of reuse on new purchases, and so on. Furthermore, a detailed quantitative formulation of the results of this study is highly desirable. 


\section{References}

Armstrong CM, Niinimäki K, Kujala S, Karell E, Lang C (2015) Sustainable product-service systems for clothing: exploring consumer perceptions of consumption alternatives in finland. J Clean Prod 97:30-39

Bhardwaj V, Fairhurst A (2010) Fast fashion: response to changes in the fashion industry. Int Rev Retail Distrib Consumer Res 20(1):165-173

Birtwistle G, Moore CM (2007) Fashion clothing-where does it all end up? Int J Retail Distrib Manag 35:210-216

Bisgaard T, Henriksen K, Bjerre M (2012) Green business model innovation: conceptualisation, next practice and policy Nordic Innovation Report. Nordic Innovation Publication, Oslo

Bruce M, Daly L (2006) Buyer behaviour for fast fashion. J Fashion Market Manag 10(3):329-344

Carlsson J, Pal R, Mouwitz P, Lidström A (2014) ReDesign kläder: Förstudie [ReDesign Clothes: Prestudy]. The Swedish School of Textiles, Borås

Caro F, Martinez-de-Albeniz V (2014) Fast fashion: business model overview and research opportunities. In: Agrawal N, Smith SA (eds) Retail supply chain management: quantitative models and empirical studies, 2nd edn. Springer, New York

Choi TM (2013) Local sourcing and fashion quick response system: the impacts of carbon footprint tax. Transp Res Part E Logist Transp Rev 55:43-54

Christopher M, Lowson R, Peck H (2004) Creating agile supply chains in the fashion industry. Int J Retail Distrib Manag 32(8):367-376

Clark H (2008) SLOW + FASHION—an oxymoron—or a promise for the future ...? Fashion Theory 12(4):427-446

Cline EL (2012) Overdressed: the shockingly high cost of cheap fashion. Portfolio/Penguin Group, New York

Cresswell JW (2007) Qualitative inquiry \& research design: choosing among five approaches, 2nd edn. Sage, Thousand Oaks

Deloitte (2013) Fashioning sustainability 2013: redesigning the fashion business. In: Christiansen, AM, Hvidsteen K, Haghshenas B (eds) Deloitte

EC (2011) Communication from the Commission to the European Parliament, the Council, the European Economic and Social Committee and the Committee of the Regions: Roadmap to a Resource Efficient Europe. European Commission, Brussels

Eisenhardt KM, Graebner ME (2007) Theory building from cases: opportunities and challenges. Acad Manag J 50(1):25-32

Ekström K, Salomonsson N (2014) Reuse and recycling of clothing and textiles: a network approach. J Macromarket 1-17

Ekvall T, Watson D, Kiørboe N, Palm D, Texie H, Harris S, . . Dahlbo H (2014) EPR systems and new business models: Reuse and recycling of textiles in the Nordic region. In: The Nordic Councils of Ministers (ed) TemaNord:Norden, Copenhagen

Ellen McArthur Foundation (2013) Towards the circular economy Economic and Business Rationale for an Accelerated Transition (vol 1). Ellen MacArthur Foundation

Farrant L, Olsen AI, Wangel A (2010) Environmental benefits from reused clothing. Int J Lifecyle Assess 15:726-736

Fleischmann M, Kuik R (2003) Production, manufacturing and logistics: on optimal inventory control with independent stochastic item returns. Eur J Oper Res 151(1):25-37

Fleischmann M, van Nunun JA, Grave B, Gapp R (2004) Reverse logistics: capturing value in the extended supply chain. ERIM Report: ERS-2004-091-LIS

Fletcher K (2010) Slow fashion: an invitation for systems change. Fashion Practice 2(2):259-266

Fletcher K (2013) Design for sustainability in fashion and textiles. In: Black S, de la Haye A, Entwistle J, Rocamora A, Root RA, Thomas H (eds) The handbook of fashion studies. Bloomsnury, London 
Fletcher K, Grose L (2012) Fashion and sustainability: design for change. Laurence King Publishers, London

Gardetti MA, Torres AL (2013) Sustainability in fashion and textiles, values, design, production and consumption. Greenleaf Publishing, Sheffield

Guardian (2015) http://www.theguardian.com/sustainable-business/2015/aug/25/hms-1m-recycling-prize-clever-overproduction-fast-fashion. Accessed 01 Sep 2015

Ho HP, Choi TM (2012) A five-R analysis for sustainable fashion supply chain management in Hong Kong: a case analysis. J Fashion Market Manag 16(2):161-175

Hvass KK (2014) Post-retail responsibility of garments: a fashion industry perspective. Fashion Market Manag 18(4):413-430

Jayaraman V, Luo Y (2007) Creating competitive advantages through new value creation: a reverse logistics perspective. Acad Manag Perspect 21(2):56-73

Joy A, Sherry JF, Venkatesh A, Wang J, Chan R (2012) Fast fashion, sustainability, and the ethical appeal of luxury brands. Fashion Theory 16(3):273-296

Kelly M (2012) In the loop. Ecotextile News, Sweden, pp 44-46

Kibert NC (2003) Extended producer responsibility: a tool for achieving sustainable development. J Land Use 19(2):503-523

Kostecki M (1998) The durable use of consumer products: new options for business and consumption. Kluwer Academic Publishers, Dordrecht

Lindhqvist T (1992) Extended producer responsibility as a strategy to promote cleaner production. In: Paper presented at the proceedings of the invitational seminar, Trolleholm Castle, Sweden

Lindhqvist T (2000) Extended producer responsibility in cleaner production: policy principle to promote environmental improvements of product systems. Ph.D., Lund University, Lund

Lindhqvist T, Lidgren K (1990) Modeller för Förlängt producentansvar [Model for extended producer responsibility], pp 7-44. Ministry of the Environment, Från vaggan till graven-sex studier av varors miljöpåverkan

Lindhqvist T, Lifset R (1997) What's in a name: producer or product responsibility? J Ind Ecol $1(2): 6-7$

Magretta J (2002) Why business models matter. Harvard Bus Rev

Masson R, Iosif L, MacKerron G, Fernie J (2007) Managing complexity in agile global fashion industry supply chains. Int J Logistics Manag 18(2):238-254

Mattila H, King R, Ojala N (2002) Retail performance measures for seasonal fashion. J Fashion Market Manag 6(4):340-351

McKinsey (2011) Resource revolution: meeting the world's energy, materials, food, and water needs McKinsey and Company Sustainability, Resource Productivity Practice. McKinsey Global Institute. www.mckinsey.com/. Accessed 17 July 2015

Mont O, Dalhammar C, Jacobsson N (2006) A new business model for baby prams based on leasing and product remanufacturing. J Clean Prod 14(17):1509-1518

Myrorna (2015) http://myrorna.se/om-myrorna/sa-gar-det-till/. Accessed 14 Aug 2015

Niinimäki K, Hassi L (2011) Emerging design strategies in sustainable production and consumption of textiles and clothing. J Clean Prod 19:1876-1883

Niinimäki K, Pedersen E, Hvass KK, Svengren Holm L (2015) Fashion industry and new approaches for sustainability. In: Muthu SS (ed) Handbook of sustainable apparel production. CRC Press, Boca Raton

Nudie (2015a) http://www.nudiejeans.com/reuse/\#/nudie-jeans-good-environmental-choice/. Accessed 14 Aug 2015

Nudie (2015b) http://www.nudiejeans.com/reuse/. Accessed 14 Aug 2015

Nudie (2015c) http://www.nudiejeans.com/recycle/. Accessed 14 Aug 2015

OECD (2001) Extended producer responsibility: a guidance manual for governments. OECD Publishing, Paris

Osterwalder A, Pigneur Y, Tucci C (2005) Clarifying business models: origins, present, and future of the concept. Commun Assoc Inf Syst 16(1). http://aisel.aisnet.org/cais/vol16/iss11/ 
Pacheco-Martins A, Pal R, Torstensson H (2014) Advanced computing techniques: new tools for fast fashion sales forecasting. In: Paper presented at the Ambience 2014, Tampere, Finland

Pal R (2015) EPR-systems and new business models for sustained value creation: a study of second-hand clothing networks in Sweden. In: Paper presented at the 15th AUTEX world textile conference, Bucharest, Romania

Palm D, Elander M, Watson D, Kiørboe N, Lyng K-A, Gíslason S (2014) Towards a new Nordic textile commitment: Collection, sorting, reuse and recycling. In: N. C. o. Ministers (ed) NORDEN Report, Copenhagen

Plank L, Rossi A, Staritz C (2012) Workers and social upgrading in 'fast fashion': the case of the apparel industry in Morocco and Romania. Austrian Foundation for Development Research (ÖFSE), Vienna

Pookulangara S, Shephard A (2014) The slow fashion process: rethinking strategy for fast fashion retailers. In: Choi TM (ed) Fast fashion systems: theories and applications. CRC Press, Leiden, pp 9-22

Re-dress (2015) http://www.re-dress.org.uk/index.html. Accessed 24 June 2015

Reuters (2012) http://www.reuters.com/article/2012/09/11/idUS56267+11-Sep2012+HUG20120911. Accessed 25 Aug 2015

Serel DA (2014) Flexible procurement models for fast fashion retailers. In: Choi TM (ed) Fast fashion systems: theories and applications. CRC Press, Leiden, pp 59-75

Stahel W (1982) The product life factor. In: Orr GS (ed) An inquiry into the nature of sustainable societies. the role of the private sector, pp 72-105. http://infohouse.p102ric.org/ ref/133/32217.pdf. Accessed 32220.32208.32015. Houston Area Research Centre, Houston

Stahel W (1994) The utilization-focused service economy: resource efficiency and productlife extension. In: Allenby B, Richard D (eds) The greening of industrial ecosystems. The National Academies

Stahel W (2007) Resource-miser business models. Int J Environ Technol Manag 7(5/6):483-495

Studio Re:design (2014) http://epi.vgregion.se/upload/Studio\%20ReDesign/Rapporter/ REDESIGN\%20-\%20FINAL.pdf. Accessed 20 Aug 2015

Sull D, Turconi S (2008) Fast fashion lessons. Bus Strat Rev 19(2):4-11

Tojo N (2004) Extended producer responsibility as a driver for design change: utopia or reality?. Lund University, Lund

Tukker A (2015) Product services for a resource-efficient and circular economy: a review. J Clean Prod 97:76-91

Wang K, Gou Q, Yang L, Siqing S (2014) Coordination of a fast fashion supply chain with profitloss sharing contract. In: Choi TM (ed) Fast fashion systems: theories and applications. CRC Press, Leiden, pp 77-92

Wikipedia (2015) Slow Fashion, https://en.wikipedia.org/wiki/Slow_Movement\#Slow_Fashion. Accessed 10 Aug 2015

WRAP (2013a) Study into consumer second-hand shopping behaviour to identify the re-use displacement effect. Project Code MDP007-001

Yunus M, Moingeon B, Lehmann-Ortega L (2010) Building social business models: lessons from the Grameen experience. Long Range Plan 43:308-325 